\section{Low aspirin use and high prevalence of pre- eclampsia risk factors among pregnant women in a multinational SLE inception cohort}

Women with systemic lupus erythematosus (SLE) carry a substantially higher risk for pre-eclampsia compared with the general population. ${ }^{1}$ Aspirin reduces the risk of pre-eclampsia in high-risk pregnancies by more than half ${ }^{2}$ and thus is recommended in SLE. ${ }^{3-5}$ The European League Against Rheumatism recommends aspirin in SLE pregnancies, particularly in those with nephritis or positive antiphospholipid antibodies (aPL). ${ }^{5}$ Despite this, little is known about current practice. Therefore, we assessed the prevalence of aspirin use in SLE pregnancies within the Systemic Lupus International Collaborating Clinics inception cohort, which has been described elsewhere. ${ }^{6}$

SLE women aged 18-45 with a pregnancy documented at one or more annual study visits (spanning 2000-2017) were included. For each pregnant visit, aspirin use, traditional pre-eclampsia risk factors (hypertension, chronic kidney disease, diabetes, nulliparity, body mass index $\geq 35$, age $>40$ ), aPL and active lupus nephritis were assessed (see variable definitions in online supplementary material). Aspirin use was compared among those with and without each/any risk factor, and over time.

We identified 475 pregnancies among 300 women. Mean SLE duration at the time of pregnancy was 5.6 years (SD 3.1). Half (51\%) of pregnancies had $\geq 1$ traditional pre-eclampsia risk factor, 34/104 (33\%) had positive aPL and 53/475 (11\%) had nephritis (table 1). Aspirin was used in 121 (25\%) pregnancies. While a third of pregnancies in Caucasians (71/209, $34 \%, 95 \%$ CI $28 \%$ to $41 \%)$ and Hispanics $(20 / 62,32 \%, 95 \%$ CI $22 \%$ to $45 \%)$ were aspirin exposed, only $9 / 88(10 \%, 95 \%$ CI $5 \%$ to $18 \%)$ and $7 / 66(11 \%, 95 \%$ CI $5 \%$ to $20 \%)$ of pregnancies in Black and Asian subjects were respectively aspirin exposed. Aspirin use did not differ among pregnancies with or without $\geq 1$ traditional risk factor $(58 / 234,25 \%$ (95\% CI $20 \%$ to $31 \%$ ) vs $63 / 241,26 \%$ (95\% CI $21 \%$ to $32 \%)$ ), any traditional risk factor individually, or nephritis (see online supplementary table 1). There was a potential trend for increased aspirin use among pregnancies with positive aPL $(13 / 34,38 \%$, $95 \%$ CI $24 \%$ to $55 \%$ ) compared with those without aPL (16/70, 23\%, 95\% CI 15\% to 34\%), although CI overlapped. Sensitivity analyses excluding multiple pregnancies within the same women yielded similar results. Aspirin use did not increase from 2000 to 2017 ( $\chi^{2}$ test for trend in proportions, $\mathrm{p}=0.13$ ).

Our study is the first to assess aspirin use in SLE pregnancies according to the presence of pre-eclampsia risk factors. Among the 475 SLE pregnancies in this prospective, multinational inception cohort, additional pre-eclampsia risk factors were present in half, while aspirin was taken in only one-quarter and did not differ from background aspirin use among the same women at non-pregnant visits (see online supplementary material). Even without considering SLE itself as a major risk factor, aspirin use was no more prevalent among those
Table 1 Characteristics of SLE pregnancies overall and according to aspirin use

\begin{tabular}{|c|c|c|c|}
\hline Characteristic & $\begin{array}{l}\text { All pregnant } \\
\text { visits } \\
(\mathrm{n}=475)^{*}\end{array}$ & $\begin{array}{l}\text { Pregnant } \\
\text { visits with } \\
\text { aspirin } \\
(n=121)\end{array}$ & $\begin{array}{l}\text { Pregnant visits } \\
\text { without aspirin } \\
(n=354)\end{array}$ \\
\hline \multicolumn{4}{|l|}{ Patient characteristic } \\
\hline Age, mean (SD) & $31.0(4.9)$ & $30.5(4.6)$ & $31.2(5.0)$ \\
\hline \multicolumn{4}{|l|}{ Ethnicity, n (\%) } \\
\hline Asian & $66(14)$ & $7 / 66$ (11) & 59/66 (89) \\
\hline Native North American & $3(1)$ & $2 / 3(67)$ & $1 / 3(33)$ \\
\hline Black & $88(19)$ & $9 / 88(10)$ & 79/88 (90) \\
\hline Caucasian & 209 (44) & $71 / 209$ (34) & 138/209 (66) \\
\hline Hispanic & $62(13)$ & 20/62 (32) & $42 / 62(68)$ \\
\hline Indian subcontinent & $25(5)$ & $8 / 25(32)$ & $17 / 25(68)$ \\
\hline Other & $22(5)$ & 4/22 (18) & 18/22 (82) \\
\hline \multicolumn{4}{|l|}{ Country, n (\%) } \\
\hline Canada & $121(25)$ & $27 / 121(22)$ & $94 / 121(78)$ \\
\hline USA & $105(22)$ & 20/105 (19) & $85 / 105(81)$ \\
\hline Mexico & $52(11)$ & 19/52 (37) & $33 / 52(63)$ \\
\hline Europe & $146(31)$ & 49/146 (34) & 97/146 (66) \\
\hline South Korea & $51(11)$ & $6 / 51(12)$ & 45/51 (88) \\
\hline Any postsecondary education, $n$ (\%) & $310 / 452(69)$ & $69 / 310(22)$ & $241 / 310(78)$ \\
\hline BMI, mean (SD) & $25.8(5.9)$ & $26.3(5.2)$ & $25.6(6.1)$ \\
\hline \multicolumn{4}{|l|}{ Obstetrical history } \\
\hline Parity, mean (SD) & $1.1(1.0)$ & $1.1(1.0)$ & $1.2(1.0)$ \\
\hline Nulliparous, n (\%) & 134/461 (29) & $37 / 134(28)$ & 97/134 (72) \\
\hline $\begin{array}{l}\text { Previous fetal loss }<24 \text { weeks, } \\
\mathrm{n}(\%)\end{array}$ & $84 / 456(18)$ & $22 / 84(26)$ & $62 / 84(74)$ \\
\hline \multicolumn{4}{|l|}{ SLE characteristics } \\
\hline Disease duration (years), mean (SD) & $5.6(3.3)$ & $5.6(3.3)$ & $5.6(3.3)$ \\
\hline SLEDAI, mean (SD) & $3.3(3.8)$ & $3.0(3.6)$ & $3.4(3.9)$ \\
\hline SLICC damage score, mean (SD) & $0.5(1.0)$ & $0.6(1.0)$ & $0.5(1.0)$ \\
\hline Any positive aPL, n (\%) & 34/104 (33) & 13/34 (38) & $21 / 34(62)$ \\
\hline LAC, n (\%) & 19/104 (18) & 6/19 (32) & $13 / 19(68)$ \\
\hline $\mathrm{ACL}, \mathrm{n}(\%)$ & $12 / 104(12)$ & $3 / 12(25)$ & 9/12 (75) \\
\hline GP1 lgG, n (\%) & 18/104 (17) & 9/18 (50) & 9/18 (50) \\
\hline Nephritis, n (\%) & $53(11)$ & $11 / 53(21)$ & $42 / 53(79)$ \\
\hline \multicolumn{4}{|l|}{ Comorbidities } \\
\hline Any renal diseaset, $\mathrm{n}(\%)$ & $83(17)$ & $17 / 83(20)$ & $66 / 83(80)$ \\
\hline $\begin{array}{l}\left.\text { CKD (eGFR } \leq 90 \mathrm{~mL} / \mathrm{min} / 1.73 \mathrm{~m}^{2}\right) \\
\mathrm{n}(\%)\end{array}$ & 43/459 (9) & $6 / 43(14)$ & $37 / 43(86)$ \\
\hline $\begin{array}{l}\text { CKD stage } \leq 3(\mathrm{eGFR} \leq 60 \mathrm{~mL} / \\
\left.\mathrm{min} / 1.73 \mathrm{~m}^{2}\right), \mathrm{n}(\%)\end{array}$ & $11 / 459(2)$ & $5 / 11(45)$ & $6 / 11(55)$ \\
\hline Hypertension, n (\%) & 79 (17) & $24 / 79(30)$ & $55 / 79(70)$ \\
\hline Taking anticoagulation, $\mathrm{n}(\%)$ & $28(6)$ & $12 / 28(43)$ & $15 / 28(54)$ \\
\hline \multicolumn{4}{|l|}{ Year of pregnancy visit } \\
\hline $2000-2004, n(\%)$ & $39(8)$ & $11 / 39(28)$ & $28(72)$ \\
\hline 2005- 2009, n (\%) & $157(33)$ & 46/157 (29) & 111/157 (71) \\
\hline $2010-2014, n(\%)$ & $218(46)$ & $52 / 218(24)$ & $166 / 218(76)$ \\
\hline 2015-2017, n (\%) & $61(13)$ & $12 / 61(20)$ & 49/61 (80) \\
\hline
\end{tabular}

${ }^{*}$ Denominator $=475$ unless otherwise stated.

tIncludes chronic kidney disease, active nephritis and/or nephrotic syndrome within the last year.

$\mathrm{ACL}$, anticardiolipin antibody; aPL, antiphospholipid antibody; BMI, body mass index; CKD, chronic kidney disease; eGFR, estimated glomerular filtration rate; GP1, anti-B2glycoprotein-1; LAC, lupus anticoagulant; SLE, systemic lupus erythematosus; SLEDAI, Systemic Lupus Erythematosus Disease Activity Index; SLICC, Systemic Lupus International Collaborating Clinics.

with other traditional indications for aspirin in pregnancy, and the majority of those with aPL and nephritis were not taking aspirin. The low aspirin use among Black SLE subjects is noteworthy given the worse reproductive outcomes observed in this population.? 
Study limitations include lack of data on gestational age and pregnancy outcomes. In addition, aspirin could have been introduced at/or following the study visit when the pregnancy was documented, highlighting the importance of the rheumatologist in reviewing aspirin use and initiating it, if not already done, in pregnant SLE women. However, assuming either a somewhat normal or a left-skewed distribution of gestational ages at the pregnant visits, a substantial proportion of visits would have taken place after 12-16 weeks' gestation, by which time aspirin should have been initiated. ${ }^{23}$

In conclusion, we have potentially identified an important gap between practices and current recommendations for the care of pregnant SLE women, and call for further studies of factors contributing to aspirin use in lupus pregnancies.

\section{Arielle Mendel, ${ }^{1}$ Sasha B Bernatsky, ${ }^{1,2}$ John G Hanly, ${ }^{3}$ Murray B Urowitz, ${ }^{4}$ Ann Elaine Clarke, ${ }^{5}$ Juanita Romero-Diaz, ${ }^{6}$ Caroline Gordon,, 8 Sang-Cheol Bae, ${ }^{9}$ Daniel J Wallace, ${ }^{10}$ Joan T Merrill, ${ }^{11}$ Jill P Buyon, ${ }^{12}$ David A Isenberg, ${ }^{13}$ Anisur Rahman, ${ }^{13}$ Ellen M Ginzler, ${ }^{14}$ Michelle Petri, $^{15}$ Mary Anne Dooley, ${ }_{18}^{16}$ Paul R Fortin, ${ }^{17}$ Dafna D Gladman, ${ }^{4}$ \\ Kristján Steinsson, ${ }^{18}$ Rosalind Ramsey-Goldman, ${ }^{19}$ \\ Munther A Khamashta, ${ }^{20}$ Cynthia Aranow, ${ }^{21}$ Meggan Mackay, ${ }^{21}$ \\ Graciela S Alarcón, ${ }^{22}$ Susan Manzi, ${ }^{23}$ Ola Nived, ${ }^{24}$ Andreas Jönsen, ${ }^{24}$ \\ Asad A Zoma, ${ }^{25}$ Ronald F van Vollenhoven, ${ }^{26}$ Manuel Ramos-Casals, ${ }^{27}$ Guillermo Ruiz-Irastorza, ${ }^{28}$ Sam Lim, ${ }^{29}$ Ken C Kalunian, ${ }^{30}$ Murat Inanc, ${ }^{31}$ Diane L Kamen, ${ }^{32}$ Christine A Peschken, ${ }^{33}$ Søren Jacobsen, ${ }^{34}$ Anca Askanase, ${ }^{35}$ Jorge Sanchez-Guerrero, ${ }^{36}$ Ian N Bruce, ${ }^{37,38}$ Nathalie Costedoat-Chalumeau, ${ }^{39}$ Évelyne Vinet ${ }^{1,2}$}

'Division of Rheumatology, McGill University Health Centre, Montreal, Quebec, Canada

${ }^{2}$ Division of Clinical Epidemiology, Research Institute of the McGill University Health Center, Montreal, Quebec, Canada

${ }^{3}$ Division of Rheumatology, Department of Medicine and Department of Pathology, Queen Elizabeth II Health Sciences Centre and Dalhousie University, Halifax, Nova Scotia, Canada

${ }^{4}$ Lupus Program, Centre for Prognosis Studies in the Rheumatic Disease and Krembil Research Institute, Toronto Western Hospital, University of Toronto, Toronto, Ontario, Canada

${ }^{5}$ Division of Rheumatology, Cumming School of Medicine, University of Calgary, Calgary, Alberta, Canada

${ }^{6}$ Department of Immunology and Rheumatology, Instituto Nacional de Ciencias Médicas y Nutrición, Tlalpan, Mexico

${ }^{7}$ Rheumatology Research Group, Institute of Inflammation and Ageing, University of Birmingham, Birmingham, UK

${ }^{8}$ Rheumatology Department, City Hospital, Sandwell and West Birmingham Hospitals NHS Trust, Birmingham, UK

${ }^{9}$ Department of Rheumatology, Hanyang University Hospital for Rheumatic Diseases, Seoul, Republic of Korea

${ }^{10}$ Cedars-Sinai Medical Centre, David Geffen School of Medicine at UCLA, Los

Angeles, California, USA

${ }^{11}$ Department of Clinical Pharmacology, Oklahoma Medical Research Foundation,

Oklahoma City, Oklahoma, USA

${ }^{12}$ Division of Rheumatology, Department of Medicine, New York School of Medicine, New York City, New York, USA

${ }^{13}$ Department of Medicine, Centre for Rheumatology, University College London, London, UK

${ }^{14}$ Department of Medicine, SUNY Downstate Medical Center, Brooklyn, New York, USA

${ }^{15}$ Division of Rheumatology, Johns Hopkins University School of Medicine, Baltimore, Maryland, USA

${ }^{16}$ Thurston Arthritis Research Center, University of North Carolina, Chapel Hill, North Carolina, USA

${ }^{17}$ Division of Rheumatology, Centre Hospitalier Universitaire de Québec et Université Laval, Québec City, Quebec, Canada

${ }^{18}$ Center for Rheumatology Research, Landspitali University Hospital, Reykjavik, Iceland

${ }^{19}$ Division of Rheumatology, Feinberg School of Medicine, Northwestern University Chicago, Chicago, Illinois, USA

${ }^{20}$ Lupus Research Unit, The Rayne Institute, St Thomas' Hospital, King's College London School of Medicine, London, UK

${ }^{21}$ Lupus Center of Excellence, Feinstein Institute for Medical Research, Manhasset, New York, USA

${ }^{22}$ Department of Medicine, University of Alabama at Birmingham, Birmingham, Alabama, USA
${ }^{23}$ Lupus Center of Excellence, Allegheny Health Network, Pittsburgh, Pennsylvania, USA

${ }^{24}$ Department of Clinical Sciences and Rheumatology, Lund University, Lund, Sweden

${ }^{25}$ Lanarkshire Centre for Rheumatology, Hairmyres Hospital, East Kilbride, UK

${ }^{26}$ Unit for Clinical Therapy Research (CliTRID), Karolinska Institute, Stockholm,

Sweden

${ }^{27}$ Josep Font Autoimmune Diseases Laboratory, IDIBAPS, Department of Autoimmune Diseases, Hospital Clínic, Barcelona, Spain

${ }^{28}$ Autoimmune Diseases Research Unit, Department of Internal Medicine, BioCruces Health Research Institute, Hospital Universitario Cruces, University of the Basque Country, Barakaldo, Spain

${ }^{29}$ Division of Rheumatology, Emory University School of Medicine, Atlanta, Georgia, USA

${ }^{30}$ University of California San Diego School of Medicine, La Jolla, California, USA

${ }^{31}$ Division of Rheumatology, Department of Internal Medicine, Istanbul Medical

Faculty, Istanbul University, Istanbul, Turkey

${ }^{32}$ Department of Medicine, Medical University of South Carolina, Charleston, South Carolina, USA

${ }^{33}$ Department of Medicine, University of Manitoba, Winnipeg, Manitoba, Canada

${ }^{34}$ Copenhagen Lupus and Vasculitis Clinic, Section 4242, Center for Rheumatology and Spine Diseases, Rigshospitalet, University of Copenhagen, Copenhagen,

Denmark

${ }^{35}$ Hospital for Joint Diseases, Seligman Centre for Advanced Therapeutics, New York

University, New York City, New York, USA

${ }^{36}$ Department of Rheumatology, Mount Sinai Hospital and University Health

Network, University of Toronto, Toronto, Ontario, Canada

${ }^{37}$ NIHR Manchester Biomedical Research Centre, Central Manchester University Hospitals NHS Foundation Trust, Manchester Academic Health Science Centre, Manchester, UK

${ }^{38}$ Arthritis Research UK Centre for Epidemiology, Centre for Musculoskeletal Research, Faculty of Biology, Medicine and Health, School of Biological Sciences, The University of Manchester, Manchester, UK

${ }^{39}$ Centre de Reference Maladies Auto-immunes et Systemiques Rares, Service de Medecine Interne, Hospital Cochin, Paris, France

Correspondence to Dr Évelyne Vinet, Research Institute of the McGill University Health Centre, Montréal, QC H4A 3S5, Canada; evelyne.vinet@mcgill.ca

\section{Handling editor Josef S Smolen}

Contributors EV had full access to all the data in this study and takes full responsibility as a guarantor for the integrity of the data and the accuracy of the data analysis. EV, AM, SBB, JGH, MBU, AEC, JRD, CG, SCB, DJW, JTM, JPB, DAI, AR, EMG, MP, MAD, PRF, DDG, KS, RRG, MAK, CA, MM, GSA, SM, ON, AJ, AAZ, RFV, MRC, GRI, SL, KCK, MI, DLK, CAP, SJ, AA, JSG, INB and NCC conceived and designed the study. EV, AM, SBB, JGH, MBU, AEC, JRD, CG, SCB, DJW, JTM, JPB, DAI, AR, EMG, MP, MAD, PRF, DDG, KS, RRG, MAK, CA, MM, GSA, SM, ON, AJ, AAZ, RFV, MRC, GRI, SL, KCK, MI, DLK, CAP, SJ, AA, JSG, INB and NCC analysed the data. EV, AM, SBB, JGH, MBU, AEC, JRD, CG, SCB, DJW, JTM, JPB, DAl, AR, EMG, MP, MAD, PRF, DDG, KS, RRG, MAK, CA, MM, GSA, SM, ON, AJ, AAZ, RFV, MRC, GRI, SL, KCK, MI, DLK, CAP, SJ, AA, JSG, INB and NCC interpreted the data and drafted the manuscript.

Funding This study was funded through a McGill University Health Centre Research Award. EV receives a salary support from a Fonds de Recherche Québec Santé Clinical Research Scholar-Junior 1 Award. SCB is supported by the Bio \& Medical Technology Development Program of the National Research Foundation funded by the Ministry of Science and ICT (NRF-2017M3A9B4050335). SJ is supported by The Danish Rheumatism Association (A-3865). AEC is supported by an Arthritis Society Chair in Rheumatic Diseases. The Hopkins Lupus Cohort is supported by a National Institutes of Health grant (R01 AR069572) awarded to MP. The Birmingham SLICC cohort was funded by a Lupus UK grant awarded to CG.

Competing interests None declared.

Patient consent for publication Not required.

Ethics approval McGill University Health Centre.

Provenance and peer review Not commissioned; externally peer reviewed.

Data sharing statement No additional data available.

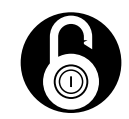

\section{OPEN ACCESS}

Open access This is an open access article distributed in accordance with the Creative Commons Attribution Non Commercial (CC BY-NC 4.0) license, which permits others to distribute, remix, adapt, build upon this work non-commercially, 


\section{Letters}

and license their derivative works on different terms, provided the original work is properly cited, appropriate credit is given, any changes made indicated, and the use is non-commercial. See: http://creativecommons.org/licenses/by-nc/4.0/.

(C) Author(s) (or their employer(s)) 2019. Re-use permitted under CC BY-NC. No commercial re-use. See rights and permissions. Published by BMJ.

- Additional material is published online only. To view please visit the journal online (http://dx.doi.org/10.1136/annrheumdis-2018-214434).

\section{A Check for updates}

To cite Mendel A, Bernatsky SB, Hanly JG, et al. Ann Rheum Dis 2019;78:1010-1012.

Received 12 September 2018

Revised 21 November 2018

Accepted 3 December 2018

Published Online First 20 December 2018

Ann Rheum Dis 2019;78:1010-1012. doi:10.1136/annrheumdis-2018-214434

\section{REFERENCES}

1 Clowse MEB, Jamison M, Myers $E$, et al. A national study of the complications of lupus in pregnancy. Am J Obstet Gynecol 2008;199:127.e1-127.e6.

2 Bujold E, Roberge S, Lacasse Y, et al. Prevention of preeclampsia and intrauterine growth restriction with aspirin started in early pregnancy: a meta-analysis. Obstet Gynecol 2010;116(2 Pt 1):402-14.

3 Visintin C, Mugglestone MA, Almerie MQ, et al. Management of hypertensive disorders during pregnancy: summary of NICE guidance. BMJ 2010;341:c2207.

4 LeFevre ML, U.S. Preventive Services Task Force. Low-dose aspirin use for the prevention of morbidity and mortality from preeclampsia: U.S. Preventive Services Task Force recommendation statement. Ann Intern Med 2014;161:819-26.

5 Andreoli L, Bertsias GK, Agmon-Levin N, et al. EULAR recommendations for women's health and the management of family planning, assisted reproduction, pregnancy and menopause in patients with systemic lupus erythematosus and/or antiphospholipid syndrome. Ann Rheum Dis 2017;76:476-85.

6 Urowitz MB, Gladman D, Ibañez D, et al. Clinical manifestations and coronary artery disease risk factors at diagnosis of systemic lupus erythematosus: data from an international inception cohort. Lupus 2007:16:731-5.
7 Buyon JP, Kim MY, Guerra MM. Predictors of Pregnancy Outcome in a Prospective, Multiethnic Cohort of Lupus Patients. Ann Intern Med 2015;163:153-63. 